\title{
Scaling, stability and synchronization in mouse-sized (and larger) cortical simulations Rajagopal Ananthanarayanan and Dharmendra S Modha*
}

\author{
Address: Cognitive Computing Department, IBM Almaden Research Center, San Jose, CA 95120, USA \\ Email: Dharmendra S Modha* - dmodha@us.ibm.com \\ * Corresponding author
}

from Sixteenth Annual Computational Neuroscience Meeting: CNS*2007

Toronto, Canada. 7-12 July 2007

Published: 6 July 2007

BMC Neuroscience 2007, 8(Suppl 2):PI87 doi:I0.I I86/I47|-2202-8-S2-PI87

(c) 2007 Ananthanarayanan and Modha; licensee BioMed Central Ltd.

Together, the two hemispheres of the mouse cortex contain, $16 \times 10^{6}$ neurons and 8,000 synapses per neuron. We have recently developed a massively parallel cortical simulator [1] that incorporates relatively simpler single compartment spiking neurons [2], spike-timing dependent plasticity (STDP) [3], and axonal delays.

We created a mouse-scale network by using 32,768 "groups" (80\% excitatory) each with 500 neurons such that each group connects to 100 randomly selected groups and each neuron from the projecting group makes a total of $\mathrm{c}=80$ synapses with the neurons of the receptive group. Excitatory groups had axonal delays uniformly ranging from 1-20 ms, and inhibitory groups had a fixed delay of $1 \mathrm{~ms}$. All simulations used a $1 \mathrm{~ms}$ time step. Using a BlueGene/L with 8,192 processors, with 4 TB of memory, using a super-threshold stimulus delivered to every neuron at $4 \mathrm{~Hz}$, we were able to simulate $5 \mathrm{~s}$ of model time in $168 \mathrm{~s}$ of real-time at a mean firing rate of $4.95 \mathrm{~Hz}$ (in stable mode). To further push the boundaries of scaling, by using $\mathrm{c}=160$ above, we created a network with $16,384,000$ neurons and 16,000 synapses per neuron. Using 16,384 processors and $8 \mathrm{~TB}$ of memory, using a 5 $\mathrm{Hz}$ stimulation, we were able to achieve $5 \mathrm{~s}$ of model time in $265 \mathrm{~s}$ of real-time at a mean firing rate of $5 \mathrm{~Hz}$ (in stable mode).
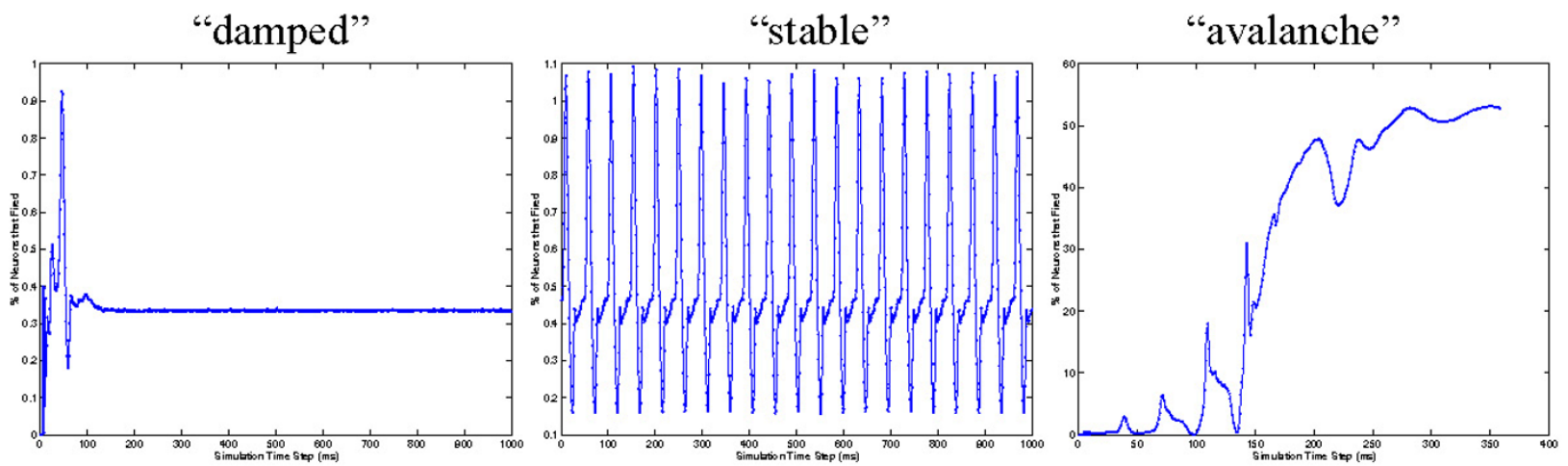

Figure I

Damped, stable and avalanche modes in network simulations. 
While it is very easy to drive a network into a damped state or into an avalanche mode, stabilizing cortical simulations is enormously difficult (p. 167, [4]), [5]. We found that the allowed maximum synaptic efficacy (which upper bounds the growth of excitatory synaptic efficacies under STDP) and the probability of the super-threshold stimulus together greatly affected the behavior of networks. We explored several models with varying numbers of synapses from 1 to 16,000 synapses per neuron. We observed that finding a range of maximum synaptic efficacies corresponding to stable models is harder to achieve for higher number of synapses per neuron if the stimulus probability is kept low. Further, there appears to be a threshold stimulus probability below which - when maximum synaptic efficacy is varied - models make a sharp transition from damped to avalanche mode. For both the networks with 16,000 and 8,000 synapses per neuron, we observed three distinct modes, namely, damped, stable, and avalanche (shown in figure 1 for the larger network).

\section{References}

I. Frye J, Ananthanarayanan R, Modha DS: Towards real-time, mouse-scale cortical simulations. CoSyNe: Computational and Systems Neuroscience, Salt Lake City, Utah; 2007.

2. Izhikevich EM, Gally JA, Edelman GM: Spike-timing dynamics of neuronal groups. Cerebral Cortex 2004, I 4:933-944.

3. Markram H, Lubke J, Frotscher M, Sakmann B: Regulation of synaptic efficacy by coincidence of postsynaptic APs and EPSPs. Science 1997, 275:213-215.

4. Abeles M: Corticonics: Neural Circuits of the Cerebral Cortex Cambridge University Press; 1991.

5. Vogels TP, Rajan K, Abbott LF: Neural network dynamics. Ann Rev Neurosci 2005, 28:357-376.

Publish with Bio Med Central and every scientist can read your work free of charge

"BioMed Central will be the most significant development for disseminating the results of biomedical research in our lifetime. " Sir Paul Nurse, Cancer Research UK

Your research papers will be:

- available free of charge to the entire biomedical community

- peer reviewed and published immediately upon acceptance

- cited in PubMed and archived on PubMed Central

- yours - you keep the copyright

Submit your manuscript here:

http://www.biomedcentral.com/info/publishing_adv.asp 